\title{
More on the Source of D-Dimer in COVID-19
}

\author{
Hau C. Kwaan ${ }^{1}$ Andrew P. Mazar ${ }^{2}$ \\ ${ }^{1}$ Division of Hematology/Oncology, Department of Medicine, \\ Feinberg School of Medicine, Northwestern University, Chicago, \\ Illinois, United States \\ ${ }^{2}$ Department of Research and Development, Monopar Therapeutics, \\ Inc., Wilmette, Illinois, United States
}

Thromb Haemost 2022;122:158-159.

The most remarkable biomarker in COVID-19 is a high plasma D-dimer level. ${ }^{1-3}$ This had been shown to be predictive for the severity of the disease $e^{4,5}$ and for thrombotic events. ${ }^{1,4,6} \mathrm{D}$-dimer is the product of plasmin degradation of crossed-linked fibrinogen monomer. ${ }^{7}$ Thus, its production requires the obligatory activity of plasmin. With the fibrinolytic shutdown in COVID-19, mostly due to elevated plasminogen activator inhibitor 1 (PAI-1) levels in plasma, ${ }^{8}$ the activation of systemic plasmin is effectively blocked. Thus, the origin of D-dimer becomes somewhat of an enigma. ${ }^{9} \mathrm{D}$ dimer is generally believed to arise from fibrin deposition in pulmonary lesions that occur in severe COVID-19 respiratory distress. As there is a hypercoagulable state in COVID-19, associated with a high fibrinogen level, tissue factor released by injured lung epithelial cells results in activation of
Address for correspondence Hau C. Kwaan, MD, Division of Hematology/Oncology, Department of Medicine, Feinberg School of Medicine, Northwestern University, 710 N. Fairbanks Court, Chicago, Illinois 60611, United States (e-mail: h-kwaan@northwestern.edu). coagulation providing ample amounts of fibrin monomers for the formation of D-dimer. Hunt and Levi point out that the source of plasmin is the pulmonary lesion, ${ }^{10}$ where urokinase plasminogen activator (UPA) as the activator of plasminogen can generate plasmin. In addition, the increased macrophages in these lesions may also provide metalloproteinases for the proteolysis of fibrin monomers. ${ }^{10}$ uPA have been observed in the bronchial lavage fluids, bronchus, pleural, and alveoli. We are providing additional information that multiple forms of uPA exists at these sites. ${ }^{11}$ Each has a different proclivity of generating plasmin (-Fig. 1). In kidney and other cells, uPA is released as single-chained uPA (scuPA) and quickly converted to twochained uPA (tcuPA) by plasmin. tcuPA then readily binds to its receptor (UPAR) which is anchored to the cell surface by a
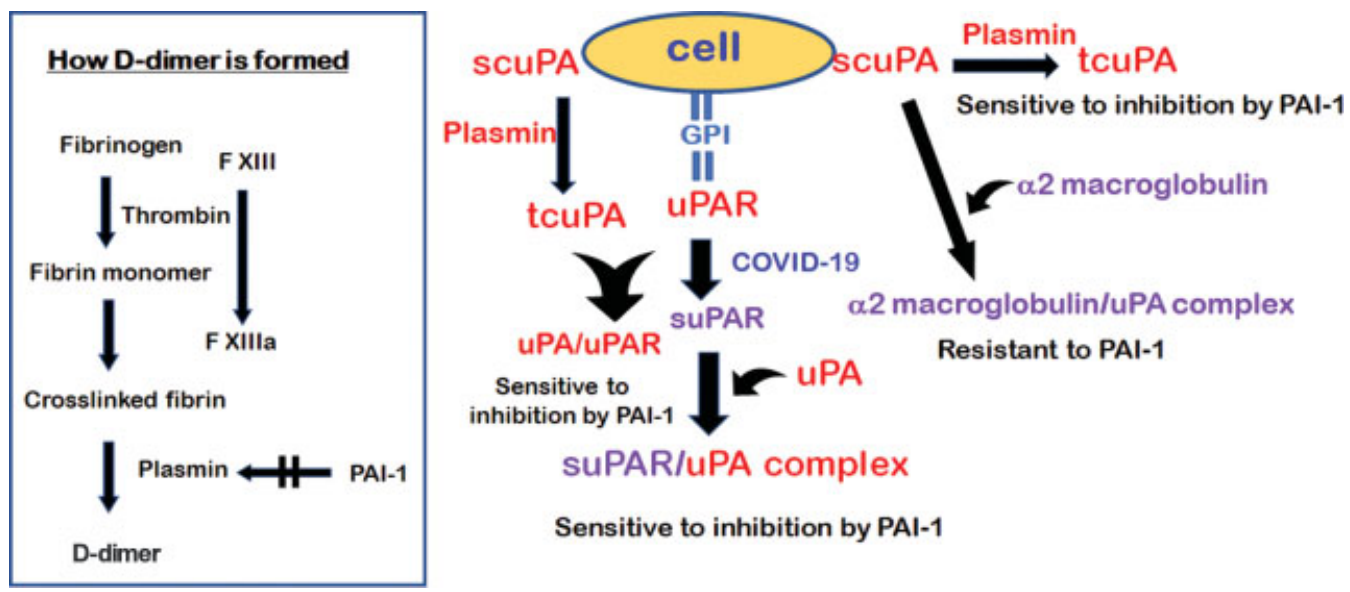

Sensitive to inhibition by PAI-1

Fig. 1 The steps in the formation of D-dimer is shown in the box on the left, showing that plasminogen activator inhibitor 1 (PAI-1) inhibits ( $\$$ ) this process. On the right, different forms of uPA including single-chain uPA (scuPA), two-chain uPA (tcuPA), uPA/uPAR complex, and scuPA/uPA complex are able to convert plasminogen to plasmin but can be sensitive to inhibition by PAI-1. The exception is when scuPA is bound to a2-macroglobulin forming $\alpha 2$-macroglobulin/uPA complex. This complex is resistant to PAl-1.

received

February 10, 2021

accepted after revision

April 20, 2021

published online

April 21, 2021 (c) 2021. Thieme. All rights reserved. Georg Thieme Verlag KG,

Rüdigerstraße 14,

70469 Stuttgart, Germany
DOI https://doi.org/ 10.1055/a-1488-3858. ISSN 0340-6245. 
glycosyl-phosphatidyl-inositol (GPI) anchor. Proteolysis of the GPI anchor will free UPAR from the cell surface forming soluble UPAR (suPAR). Plasma suPAR is high in COVID-19 and is predictive for severity of disease and for extent of organ injury. ${ }^{12}$ With its ligand (uPA), it can also generate plasmin from plasminogen.

In the case of formation of D-dimer in COVID-19, the issue is how much plasmin generating potential does each form of uPA has in the affected organs. This obviously depends on their respective sensitivity to the inhibitory action of PAI-1. PAI-1 level is high in COVID-19. ${ }^{8}$

On the cell surface, tcuPA forms a complex with its receptor uPAR. The UPA/uPAR complex is active in generating plasmin, but its action is effectively inhibited by PAI-1 in the vicinity. On the other hand, the single chain zymogen form of UPA (scuPA) is less sensitive to PAI- 1 inhibition by virtue of its' forming a complex with $\alpha 2$-macroglobulin. This complex is resistant to the inhibition by PAI- 1 and thus presents an alternative pathway for plasminogen activation. ${ }^{13}$ scuPA injected into the injured pleural cavity has been found to be a source for a slow-release form of fibrinolytic activity. ${ }^{13}$ On the other hand, plasmin and other proteases convert scuPA to two chain uPA (tcuPA), which is readily inhibited by PAI-1. Thus, it can be seen that during the course of COVID19 , these components of the fibrinolytic system, namely, uPA in its various forms and PAI-1, will influence the amount of plasmin generation and the ensuing D-dimer formation.

A full understanding of the complex interactions of active PAI-1, scuPA, tcuPA, UPAR, and suPAR in the generation of active plasmin in involved organs in COVID-19 may explain the utility of D-dimer level as a biomarker in assessing the severity of the disease. How D-dimer values may assist in the management of anticoagulation in COVID-19 remains to be explored.

\section{Conflict of Interest}

None declared.

\section{References}

1 Hayıroğlu MI, Çınar T, Tekkeşin AI. Fibrinogen and D-dimer variances and anticoagulation recommendations in Covid-19: current literature review. Rev Assoc Med Bras (1992) 2020;66 (06):842-848

2 Tang N, Li D, Wang X, Sun Z. Abnormal coagulation parameters are associated with poor prognosis in patients with novel coronavirus pneumonia. J Thromb Haemost 2020;18(04):844-847

3 Levi M, Thachil J, Iba T, Levy JH. Coagulation abnormalities and thrombosis in patients with COVID-19. Lancet Haematol 2020;7 (06): e438-e440

$4 \mathrm{Bi} \mathrm{X}, \mathrm{Su}$ Z, Yan H, et al. Prediction of severe illness due to COVID-19 based on an analysis of initial fibrinogen to albumin ratio and Platelet count. Platelets 2020;31(05):674-679

5 Lippi G, Favaloro EJ. D-dimer is associated with severity of coronavirus disease 2019: a pooled analysis. Thromb Haemost 2020;120(05):876-878

6 Zhou F, Yu T, Du R, et al. Clinical course and risk factors for mortality of adult inpatients with COVID-19 in Wuhan, China: a retrospective cohort study. Lancet 2020;395(10229):1054-1062

7 Weitz JI, Fredenburgh JC, Eikelboom JW. A test in context: Ddimer. J Am Coll Cardiol 2017;70(19):2411-2420

8 Zuo Y, Warnock M, Harbaugh A, et al. Plasma tissue plasminogen activator and plasminogen activator inhibitor-1 in hospitalized COVID-19 patients. Sci Rep 2021;11(01):1580

9 Ibanez C, Perdomo J, Calvo A, et al. High D dimers and low global fibrinolysis coexist in COVID19 patients: what is going on in there? J Thromb Thrombolysis 2021;51(02):308-312

10 Hunt BJ, Levi M. The source of elevated plasma D-dimer levels in COVID-19 infection. Br J Haematol 2020;190(03):e133-e134

11 Tucker TA, Idell S. The contribution of the urokinase plasminogen activator and the urokinase receptor to pleural and parenchymal lung injury and repair: a narrative review. Int J Mol Sci 2021;22 (03): 1437

12 Chalkias A, Mouzarou A, Samara E, Xanthos T, Ischaki E, Pantazopoulos I. Soluble urokinase plasminogen activator receptor: a biomarker for predicting complications and critical care admission of COVID-19 patients. Mol Diagn Ther 2020;24(05):517-521

13 Komissarov AA, Mazar AP, Koenig K, Kurdowska AK, Idell S. Regulation of intrapleural fibrinolysis by urokinase-alpha-macroglobulin complexes in tetracycline-induced pleural injury in rabbits. Am J Physiol Lung Cell Mol Physiol 2009;297(04): L568-L577 